This item was submitted to Loughborough's Research Repository by the author.

Items in Figshare are protected by copyright, with all rights reserved, unless otherwise indicated.

\title{
Does mathematics look certain in the front, but fallible in the back?
}

PLEASE CITE THE PUBLISHED VERSION

http://dx.doi.org/10.1177/0306312711424789

PUBLISHER

SAGE Publications ()$^{\text {The Author(s) }}$

VERSION

AM (Accepted Manuscript)

LICENCE

CC BY-NC-ND 4.0

REPOSITORY RECORD

Greiffenhagen, Christian, and Wes Sharrock. 2019. "Does Mathematics Look Certain in the Front, but Fallible in the Back?". figshare. https://hdl.handle.net/2134/13250. 
This item was submitted to Loughborough's Institutional Repository (https://dspace.lboro.ac.uk/) by the author and is made available under the following Creative Commons Licence conditions.

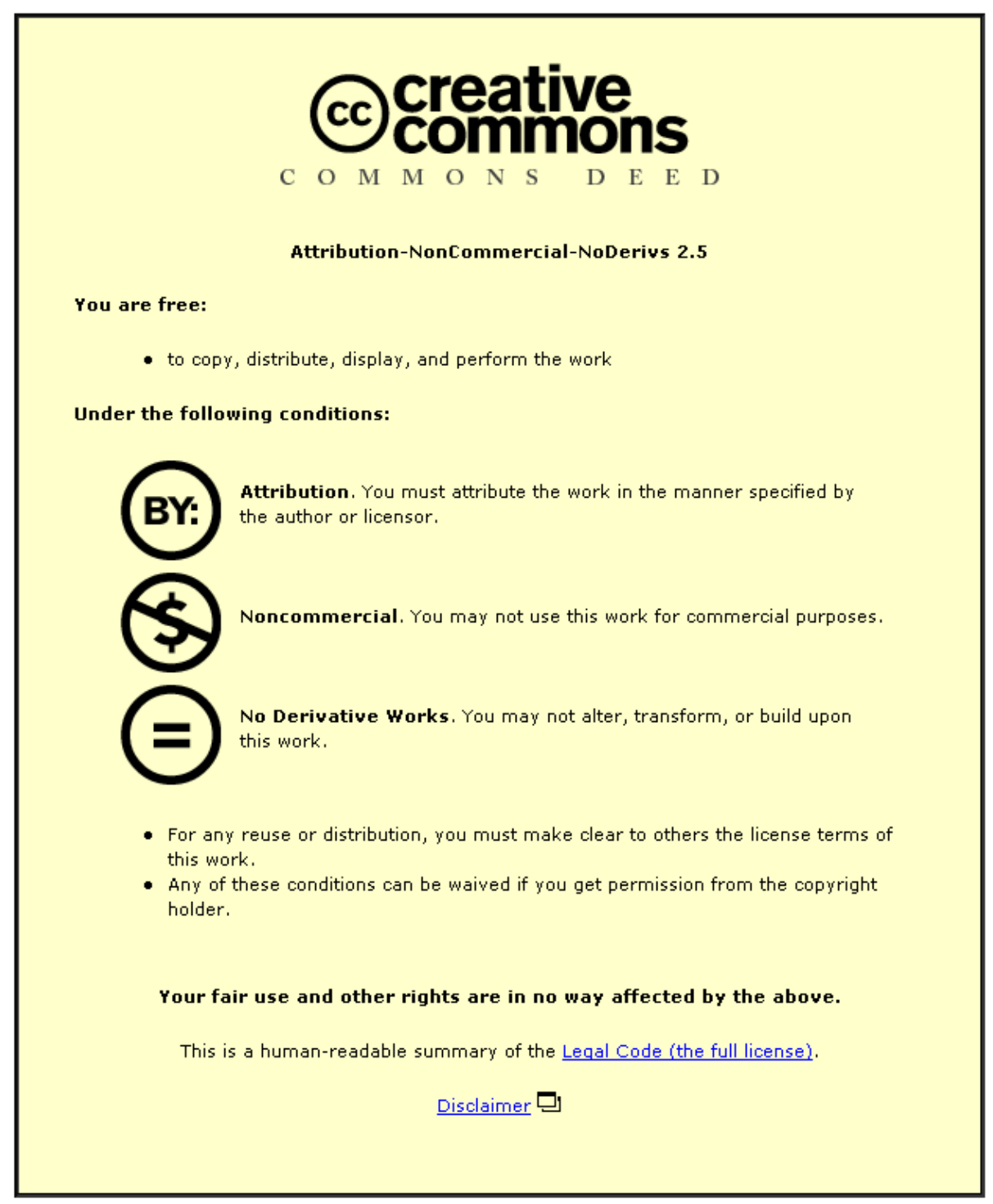

For the full text of this licence, please go to: http://creativecommons.org/licenses/by-nc-nd/2.5/ 


\title{
Christian Greiffenhagen
}

School of Social Sciences, University of Manchester

Wes Sharrock

School of Social Sciences, University of Manchester

\begin{abstract}
In this paper we re-examine the implications of the differences between 'doing' and 'writing' science and mathematics, questioning whether the way that science and mathematics are presented in textbooks or research articles creates a misleading picture of these differences. We focus our discussion on mathematics, in particular, on Reuben Hersh's formulation of the contrast in terms of Goffman's dramaturgical frontstage-backstage analogy and his claim that various myths about mathematics only fit with how mathematics is presented in the 'front', but not with how it is practised in the 'back'. By investigating examples of both the 'front' (graduate lectures in mathematical logic) and the 'back' (meetings between supervisor and doctoral students) we examine, firstly, whether the 'front' of mathematics presents a misleading picture of mathematics, and, secondly, whether the 'front' and 'back' of mathematics are so discrepant that mathematics really does look certain in the 'front', but fallible in the 'back'.
\end{abstract}

Keywords: mathematics, fallibilism, ideology, certainty, myths

\section{Corresponding author:}

Christian Greiffenhagen, School of Social Sciences, University of Manchester, Arthur Lewis Building, Manchester M13 9PL, UK

Email: christian.greiffenhagen@manchester.ac.uk 
In this paper we take another look at the implications of the differences between 'doing' and 'writing' science; that is, the differences between how science is practised in the laboratory and how the results of those practices are subsequently presented in publications, lectures, or textbooks. We will focus on the applicability of this contrast to mathematics and discuss some empirical examples, but we are initially concerned with how the contrast is formulated in the literature on philosophy and sociology of science more generally (see, for example, Holmes, 1987; Schickore, 2008). ${ }^{\mathrm{i}}$

It is not itself surprising or of epistemological importance that there are differences between the various activities that are part of creating a particular product (a movie, a novel, or a scientific paper) and the properties of the final product. Why the contrast between 'doing' and 'writing' is seen as significant in the case of science derives from the view that science is presented in a way that misrepresents or mystifies how it is actually done. In that view, scientific writing creates a misleading picture of science, not only to those who do not know much about it (outsiders), but possibly also to practitioners themselves (insiders). ${ }^{\mathrm{ii}}$

With respect to the experimental sciences, the title of Peter Medawar's (1963) paper 'Is the scientific paper a fraud?' was an eye-catching way of formulating the issue. Medawar's intention was not to claim that scientific papers are literal frauds (in the sense that they are based on obfuscated, fabricated, or manipulated data), but that their presentational conventions misrepresent the actual nature of the research they report. In his view, papers were written as though they had issued from an inductive method, when in reality they were produced by falsificationist procedures. Following Medawar, scientific papers have been seen to purvey a picture of science that fits an ideology rather than actual practice. iii In the case of mathematics, Reuben Hersh (1991) formulated the contrast by adapting Goffman's (1956) dramaturgical metaphor to mathematics, to argue that 'mathematics has a front and a back', where the 'front' refers to how mathematics is presented (what Pólya [1954: vi] called 'finished mathematics') and the 'back' to how it is actually done (what Pólya called 'mathematics in the making'). Like Medawar, Hersh argued that the 'front' is remarkably different from the 'back' and that the separation makes possible the 
perpetuation of various myths about mathematics (in particular, that mathematics is an absolutely certain and a comprehensively logical affair).

Much of this argument is based on the view that, depending on whether one looks at how science is written (the 'front') or is practiced in the laboratory (the 'back'), two different pictures of science emerge, a view that was captured in Latour's (1987) two-faced Janus figure of science (looking back to 'all made science' and forward to 'science in the making'). The picture that is supposed to be conveyed by the 'front' is the empiricist view of science that has been the target of recent philosophy and sociology of science. Crudely, this empiricist view is seen as picturing science as providing unmediated representations of an independent and determinate reality. In contrast, examining the 'back' reveals a different picture of the artifactual nature of scientific facts and theories and the fallible human process that constitutes them. In the case of mathematics, it is argued that an 'absolutist' or 'formalist' picture of mathematics fits with the 'front', while a 'fallibilist' or 'constructivist' picture emerges from the 'back'. What is at stake is not only the 'correctness' of the two pictures, but their implications for the public authority of science. The first picture presents science as though it is entitled to absolute authority, meaning that non-scientists should assent to whatever they are told by the 'experts', because what they are told cannot possibly be mistaken. The second, alternate, picture is meant to liberate people from the first one by questioning the impression that science deserves such absolute authority, and even suggesting that it is no more than just another ideology.

This polemical contrast between the two pictures presents them as conflicting, incommensurable, or radically different. Our aim in this paper is to de-polarize the contrast between the 'front' and the 'back' by looking at examples from both sides of the divide, using video-recordings of graduate lectures and doctoral supervision meetings respectively. Our goal is not to provide a characterization of how mathematics is 'generally' done, but to use our materials to dissolve the rigidity of the front/back contrast. Specifically, we engage with two questions:

(1) In which sense is the presentation of mathematics in the 'front' misleading? 
(2) In which sense are the 'front' and the 'back' of mathematics radically divergent?

With respect to (1), we question whether what happens in the 'front' actually fits the traditional (formalist or Platonist) picture of mathematics (which is the basis for the charge that the presentation of mathematics is misleading). With respect to (2), we argue that there is more 'front' in the 'back' (and vice versa) than is assumed in the debate. We argue that the treatment of the 'front' and the 'back' as a contrastive pair downplays the continuity of the two, in particular, that the 'finished' product in the 'front' is a later stage and product of the 'currently unfinished' work in the 'back'.

Of course, there are differences between the way mathematics is presented in lectures and how it is practised at the blackboard in a research context, but we argue that this does not mean that there are different standards of certainty or forms of reasoning involved. Of course, questionable conceptions of mathematics circulate, but since many famous mathematicians such as Hilbert or even Euclid are among those who have exposed such misconceptions, it cannot be the exposure to the 'back' that immunises people against mythical conceptions. People may have wrong ideas about mathematics, but we question whether these are direct results of the way textbooks, lectures, and other publications present mathematics. 


\section{The supposed segregation of 'front' from 'back' in mathematics}

There is likely be no disagreement that mathematics enjoys a special, even unique, place in (at least) Western culture. Mathematics is often placed at the pinnacle of rational thought, exceeding even the position of the natural sciences because of the crystalline clarity and associated cast-iron certainty of its results (see, e.g., Kline, 1980: 4; Tymoczko, 1986: xiii; Ernest, 1991: xi). Furthermore, many people find anything beyond elementary mathematics inaccessibly difficult, consequently supposing that the ability to do more advanced mathematics is a criterion of superior intelligence.

But what is the basis for thinking mathematics deserves such elevated standing? There are ideas about the 'nature of mathematics' that have been in circulation for a long time (some of them going back at least to Ancient Greece). The first is the certainty of mathematical results. As Henrion (1997: 235) puts it:

What is it that distinguishes mathematical knowledge from other forms of knowledge? Students of all ages, whether they are studying algebra, trigonometry, geometry, or calculus, would agree on one universal theme: Mathematics is beyond doubt. A mathematical statement is either right or wrong, and any true statement can be proven. Moreover, once it is proved true, it can never later turn out to be false.

The second is the logical character of mathematical reasoning - of arriving at those results. That is to say, mathematics may appear to have a special method, "pure logical reason' (or 'Reason' with a capital R), which generates its certain results by operating strictly according to the laws of logic. Hersh (1991: 130) provides a succinct characterization of this:

Mathematics possesses a method, called 'proof' or sometimes 'rigorous proof', by which one attains absolute certainty of the conclusions, given the truth of the premises.

These ideas have been questioned and characterized as myths ${ }^{\mathrm{iv}}$ or ideologies ${ }^{v}$. Since important aspects of these ideas are often attributed to the Ancient Greeks, Davis and Hersh (1981: 325) speak of the 'Euclid myth': 
What is the Euclid myth? It is the belief that the books of Euclid contain truths about the universe which are clear and indubitable. Starting from self-evident truths, and proceeding by rigorous proof, Euclid arrives at knowledge which is certain, objective, and eternal. Even now, it seems that most educated people believe in the Euclid myth. Up to the middle of late nineteenth century, the myth was unchallenged. Everyone believed it. It has been the major support for metaphysical philosophy, that is, for philosophy which sought to establish some a prior certainty about the nature of the universe.

As Davis and Hersh note, up until the middle of the nineteenth century, these ideas were relatively unchallenged in the philosophical literature. However, as a result of a variety of mathematical developments, starting with the discovery of non-Euclidean geometries and culminating with the production of Gödel's Incompleteness Theorems in the 1930s, the belief in the absolute certainty of mathematics was shattered and alternative conceptions of mathematics started to emerge. The aim of much recent work in philosophy, sociology, and educational studies of mathematics has been to expose and demystify the traditional mythology (e.g., Kline, 1980; Davis and Hersh, 1981; Wilder, 1981; Kitcher, 1983; Tymoczko, 1986; Livingston, 1986; Aspray and Kitcher, 1988; Lave, 1988; Echeverria et al., 1992; Gillies, 1992; Restivo et al., 1993; Ernest, 1991, 1998; Hersh, 2005).

Despite the fact that the 'loss of certainty' (Kline, 1980) began more than a century ago and has been widely publicized, it seems that many of the myths about mathematics still persist. What explains their enduring presence? It has been argued that one important source of these myths is the way mathematics is presented in journals, conferences, textbooks, lectures, and so forth. The impression that mathematical results are certain may be a result of the fact that mathematical publications contain only the finished products of mathematical investigations. Typically, they do not mention all the things that did not work out, the reasons why certain things were preferred over others, or how the final theorem was evolved and modified during the course of proving. Standard mathematical publications have scarcely any historical elements, and, unlike scientific papers, do not even feature 'methods' statements. Similarly, the impression that mathematics results are reached through a special method may be a result of how mathematics is presented in textbooks, journal articles, and lectures; in particular, the standard modern 
'definition-theorem-proof' (DTP) format. vi This format may be taken to suggest that a mathematician started with clearly stated definitions on the basis of which he or she formed a conjecture, and then just wrote out the steps of the proof unhesitatingly one after the other. The format gives little or no information on how the definitions, theorems, or proofs were found, how they were modified in the course of the inquiry, or what the 'real' temporal development was. vii

Campbell, for example, argues that although Euclid's axiomatic procedure is a perspicuous way of presenting mathematics (since it highlights the assumptions, makes it easier to find gaps in the proof, etc.), it also carries with it a danger, since it may lead novices (students) to think that it is a representation of the reasoning that led to the final product (which, in turn, may lead students to try to reproduce such reasoning when doing mathematics themselves, which is impossible to do):

Euclid's axiomatic procedure is a breakthrough; it is a procedure for the unification of material. It allows key assumptions to stand out. It allows for systematic procedures of verification. But so long as students are misled into believing that the polished jewels are the actual reasoning rather than the end product of reasoning, just so long will it be that Euclidean geometry will remain a curse rather than a blessing to the teaching of reasoning. (Campbell, 1976: 342)

The mathematician Armand Borel similarly argues that since mathematical papers do not mention various aspects of the investigative work, they give an impression that may mislead people to conceive of mathematicians as 'thinking machines':

You should not believe that mathematicians are just thinking machines who always proceed in steps clearly planned with implacable logic. This impression is often given by papers. Those are organized for maximal efficiency of the exposition; omitting all the false leads, they often proceed in an order inverse to that which led to the discovery. (Borel, 1994: 144)

The dangers of the ways that textbooks and lectures present mathematics, ${ }^{\text {viii }}$ lead Ernest to speak of 'pedagogical falsification':

Lakatos (1976) and others have criticized the pedagogical falsification perpetrated by the standard practice of presenting advanced learners with the sanitized outcomes of mathematical enquiry. Typically advanced mathematics text books conceal 
the processes of knowledge construction by inverting or radically modifying the sequence of transformations used in mathematical invention, for presentational purposes. The outcome may be elegant texts meant for public consumption, but they also generate learning obstacles through this reformulation and inversion. (Ernest, 2008: 67)

Like Campbell and Borel, Ernest argues that the standard format of presenting mathematics does not contain a description of the actual sequence of knowledge production, and thus does not allow students to learn how to make mathematical discoveries for themselves. Ernest's formulation, however, is also sharper than those of Campbell and Borel. He speaks of 'falsification' and 'conceal[ment]', suggesting a more active role of the author of the text in creating these potentially negative aspects deliberately.

In sum, the source of the various myths about mathematics is attributed to the differences between how mathematics is presented from how it is actually practised. Hersh (1991) crystallizes this contrast by applying to mathematics Goffman's (1956) dramaturgical model of social establishments as divided between 'front' and a 'back' regions. ${ }^{\text {ix }}$ In Goffman's terms, social establishments are differentiated into spatially and/or socially segregated 'regions' by the need to project and sustain images through control of information. The 'front' region is the area in which a 'performance' is presented to a public, but the credibility of that performance is sustained by activities that need to be kept 'backstage' since awareness of them might be distracting from, and either disruptive or discrediting of, the performance. Thus, in a restaurant, the 'front' is the dining area where customers are offered neatly presented dishes, which, of course, are the product of various 'backstage' activities in the kitchen. Furthermore, while the dining area is often quiet, neat, and tidy, the kitchen is smelly, noisy, and chaotic. There may also be real discrepancies in the behaviour of the waiting staff who may be politely subordinate in view of the customers, but disrespectful, even contemptuous, out of sight.

One carry-over form Goffman's model into Hersh's use is the idea that what goes on 'in the back' must be incongruous with what is presented 'out front':

In this sense of the term, the 'front' mathematics is mathematics in 'finished' form, as it is presented to the public in 
classrooms, textbooks, and journals. The 'back' would be mathematics as it appears among working mathematicians, in informal settings, told to one another in an office behind closed doors.

Compared to 'backstage' mathematics, 'front' mathematics is formal, precise, ordered and abstract. It is separated clearly into definitions, theorems, and remarks. To every question there is an answer, or at least, a conspicuous label: 'open question'. The goal is stated at the beginning of each chapter, and attained at the end.

Compared to 'front' mathematics, mathematics 'in back' is fragmentary, informal, intuitive, tentative. We try this or that, we say 'maybe' or 'it looks like'. (Hersh, 1991: 128)

Hersh uses the contrast between 'front' and 'back' to explain the origin of the myths associated with mathematics. Although mathematicians themselves may well know that their work does not conform to the 'official' image of mathematics, ${ }^{\mathrm{x}}$ they actively perpetuate the mythology through their publications and educational practices. The way Hersh talks about 'the public', however, introduces some confusion, as he seems to suggest that mathematical journals are directed to 'the public' as opposed to working mathematicians. Indeed, such an interpretation is forced on us by the following passage:

... the front/back separation makes possible the preservation of a myth .... By a myth we shall mean simply taking the performance seen from up front at face value; failing to be aware that the performance seen 'up front' is created or concocted 'behind the scenes' in back. This myth, in many cases, adds to the customer's enjoyment of the performance; it may even be essential. ...

Mathematics, too, has it myths. One of the unwritten criteria separating the professional from the amateur, the insider from the outsider, is that the outsiders are taken in (deceived), the insiders are not taken in. (Hersh, 1991: 129)

This passage nicely captures the issue as Hersh sees it: it is not necessarily practitioners who are misled by the way that mathematics is presented in the 'front', but outsiders, amateurs, or novices. And what is it that these people fail to see? That the definitions, theorems, and proofs that are presented so neatly are the result of various activities (which include guesses, hunches, trials and errors) not reported in

Greiffenhagen, C. and W. Sharrock (2011). Does mathematics look certain in the front, but fallible in the back? Social Studies of Science 41 (6), 839-866. 
the 'front' presentation. This way of presenting may contribute to their 'enjoyment', ${ }^{\mathrm{i}}$ but it gives a false impression of what mathematics 'is really like'. Note that Hersh here is not arguing about the efficiency of teaching technical mathematical skills (in contrast to, say, Pólya), but rather about how the way that mathematics is taught and presented conveys a particular picture of mathematics. To exaggerate Hersh's argument: if mathematical papers and textbooks were set out differently, the Euclid myth would perhaps never have arisen.

So why do mathematicians not present mathematics in a way that is more faithful to the reality of mathematical practice? Here, Hersh suggests that there is an advantage for mathematics and mathematicians to present mathematics in the 'traditional' way. Thus mathematicians may not be themselves misled by the Euclid myth, but it may be in their interest for others to believe it:

By calling these beliefs myths, I am not declaring them to be false. A myth need not be false to be a myth. The point is that it serves to support or validate some social institution ....

... the unity, universality, objectivity, and certainty of mathematics are beliefs that support and justify the institution of mathematics. (For mathematics, which is an art and a science, is also an institution, with budgets, administrations, publications, conferences, rank, status, awards, grants, etc.)

Part of the job of preparing mathematics for public presentation - in print or in person - is to get rid of all the loose ends. If there is disagreement whether a theorem has really been proved, then that theorem will not be included in the text or the lecture course. The standard style of expounding mathematics purges it of the personal, the controversial, and the tentative, producing a work that acknowledges little trace of humanity, either in the creators or the consumers. This style is the mathematical version of 'the front'.

Without it, the myths would lose much of their aura. If mathematics were presented in the same style in which it is created, few would believe in its universality, unity, certainty, or objectivity. (Hersh, 1991: 130-131)

This brings us to the heart of the issue. Hersh argues that the style in which mathematics is presented creates the 'aura' of certainty and objectivity that 
surrounds mathematics. This style creates the impression that mathematics produces absolutely certain knowledge based on mechanically logical, deductive reasoning. The impression of absolute certainty results because there is no mention of any disagreements or controversies, nor any reports of all the mistakes and errors made on the way. Furthermore, the 'impersonal', 'objective', or 'authoritative' style in which mathematical texts are written, xii 'acknowledges little trace of humanity', and thus seems to deny any human involvement in the development of new mathematical knowledge, creating the impression that mathematics is not something that mere humans can do. Accordingly, mathematical results are presented with overwhelming self-confidence, as if there could be no possibility of ever getting them wrong. Non-mathematicians would seem to have no choice but to accept whatever mathematicians tell them is so. ${ }^{\text {.iii }}$

Hersh is ambiguous on the question whether mathematicians who 'prepare' these texts and thereby 'purge' them of 'the personal, the controversial, and the tentative', do so calculatively. On the one hand, he argues that 'there is nothing sinister in this separation' (p. 127), but on the other, he speaks of the backstage activities as going on 'behind closed doors' (p. 128), which seems conspiratorial. Other authors formulate the issue more directly. For example, Ernest speaks of 'conceal[ment]' while Henrion (1997: 249) argues that '[o]ne reason that the mathematics community is not more active in conveying a more accurate picture of mathematics is that much of the power and prestige of mathematics comes from its claim to certainty and its image as an "exact science".'

So what kind of picture of mathematics would we get if we were to observe how mathematics is 'actually done' 'behind closed doors'? The most common characteristics mentioned in the literature are the following:

- mathematicians are sometimes uncertain about their results;

- mathematical problem-solving does not proceed by linear deduction;

- mathematicians make mistakes in their work and therefore have to revise it, even to start again; 
- at many stages in a project, there will be plenty of loose ends.

Table 1 provides a summary of the supposed differences.

\begin{tabular}{|l|l|}
\hline 'FRONT' & 'BACK' \\
\hline certain and final results & uncertainty, guesses, conjectures \\
\hline no mistakes & mistakes, false starts, controversies \\
\hline no loose ends & $\begin{array}{l}\text { open questions, things not worked } \\
\text { through }\end{array}$ \\
\hline deductive reasoning & plausible / intuitive reasoning \\
\hline
\end{tabular}

Table 1: The supposed differences between the 'front and 'back' regions of mathematics

These features of the 'back' of mathematics offer an alternative picture of mathematics, according to which mathematics is seen as fallible, uncertain, and contingent. In contrast to what people may believe, mathematical results, once published, are - and have been - open to revision, and not beyond all possibility of doubt. Furthermore, mathematical reasoning is less deductive than the 'front' presents it, but is based on hunches and guesses just like other human activities.

An important source of proponents of the second picture has been Lakatos's 'fallibilist' philosophy of mathematics. ${ }^{\text {xiv }}$ In Proofs and Refutations, Lakatos (1976) provides a 'rational reconstruction' of the history of a mathematical problem and its solution, namely Euler's theorem that the number of vertices $(V)$, edges $(E)$, and faces $(F)$ of all polyhedra is $V+F-E=2$. Lakatos argues that when one investigates the history of that theorem, one finds that the theorem was not stated and then proved definitely once and for all, but rather that it was revised many times in different ways as new counterexamples came to light. Through his historical reconstruction (recreated as an imagined dialogue in a classroom) Lakatos shows that aspects of proofs, definitions, and theorems are sometimes challenged and susceptible to change. 
We will take up the alternative picture and the way that Lakatos has been used after having given our empirical examples, but for now we just want to note that Lakatos's 'rational reconstruction' is not based on access to previously private aspects of mathematicians' work, but rather on published research articles which are part of the 'front' of mathematics. This fact alone shows the paradox involved in using Lakatos to argue that the 'front' of mathematics presents a misleading picture of mathematics. On the one hand, it is argued that the 'front' projects an 'absolutist' picture of mathematics. On the other hand, the main inspiration for an alternative picture of mathematics derives from his 'fallibilist' picture of mathematics, which in turn is derived from the public record that is part of the 'front'. Although Lakatos, like many other critics, attacks formalist or absolutist view of mathematics, he does not base his attack on a distinction between 'front' and 'back'. In fact, his argument could be seen as an attempt to dispel the contrast between the context of discovery (the 'back') and the context of justification (the 'front'), since he emphasizes the role of proof not just as tool for justification but also for making discoveries (see Ernest, 1998: 127).

Our argument is not that there is no value in 'looking behind the scenes', but that it is questionable as to whether increased familiarity with what goes on 'in the mathematical back' will lead to any significant revision of understanding of what is on show 'out front'. We therefore prefer the work of Pólya (1957 [1945], 1954, 1981 [1962, 1965]) on the heuristics of mathematics discovery, which together with Popper's philosophy was the main inspiration for Lakatos. Pólya questions the strict separation between the context of discovery and the context of justification, and attempts to dispel the idea that the context of discovery belongs entirely to psychology. His conception of 'modern heuristics' is an attempt to formulate the means and methods of mathematical problem solving: the systematic aspects of mathematical reasoning/guessing 'in the back'. The main aim of Pólya's work is pedagogical: that is, he wants to provide both teachers and students with explicit heuristics, rather than letting them pick these up as an unformalised part of their training. Accordingly, his greatest influence has been in mathematics education (Schoenfeld, 1987). Although Pólya also argues that mathematics has 'two faces' (1957 [1945]: vii) and he distinguishes between 'demonstrative' and 'plausible' reasoning (1954: vi) - between learning by proving and learning by guessing - these 
are not linked to two different and opposing pictures of mathematics (one a misrepresentation, the other not). For Pólya, both of these are seen as part of mathematics: 'they do not contradict each other; on the contrary, they complete each other' (p. vi). In other words, a 'correct' picture of mathematics would include aspects of both.

Apart from Pólya, numerous recent sociological and historical studies have exhibited different aspects of the practice of mathematics. To mention just a few: Livingston's $(1986,1999,2006)$ ethnomethodological investigations of the work involved in reading (understanding) mathematical proofs, MacKenzie's (1993, 1999, 2001) studies of the use of computers in mathematical problem solving, Merz and KnorrCetina's (1997) analysis of collaborative problem-solving practices among theoretical physicists, Netz's (1999) historical exploration of the role of diagrams and other notational features in Greek mathematics, Heintz's $(2000,2003)$ ethnography of research mathematicians at the Max Planck Institute for Mathematics, Rosental's $(2003,2008)$ analysis of a controversy over a theorem and proof in fuzzy logic, and Warwick's (2003) history of the interplay of educational practices (in particular: the Cambridge exam system) and mathematical innovation. All these studies reveal important and interesting aspects of how mathematics is done (typically, but not exclusively, in the 'back'). However, since the contrast between 'doing' and 'writing' mathematics does not feature heavily in these studies, we do not discuss these extensively. Instead, we want to look at empirical examples, both from the 'front' and the 'back'.

\section{Mathematical lectures: The 'front'}

We have been studying different aspects of mathematicians' practices. In one study, we attended and recorded three different graduate lecture courses in mathematical logic over several months. Mathematical lectures, as well as mathematical textbooks, are one example of mathematics in the 'front'. They present 'settled' mathematics and thus, in a sense, are far removed from the 'hurly burly' of mathematics-in-the-making. Furthermore, the presentation is typically done through a long 'monologue' with little or no input from the students. For the most part, the lecturer is 'talking-writing' at the blackboard, giving definitions, theorems, and proofs 
of those theorems, which are typically available to students in the form of written lecture notes distributed at the start of the course (Krantz, 1999: 50).

We will first present a short fragment that in our view seems to fit Hersh's characterization of the 'front'. We will then argue that it only fits in a limited way and that Hersh's characterization to some extent misconstrues what goes on in this particular case. We then provide a selection of remarks by various lecturers to show that many of the aspects that according to Hersh are absent from the 'front', are although not commonly - on occasion present in the 'front'.

The following example, which involves the setting out of a well established theorem and proof, at first sight, fits with Hersh's picture of the 'front'. There are two blackboards present in this room and the lecturer first writes, at the top right corner of the right board, a formulation of a theorem (Figure 1). ${ }^{\mathrm{xv}}$

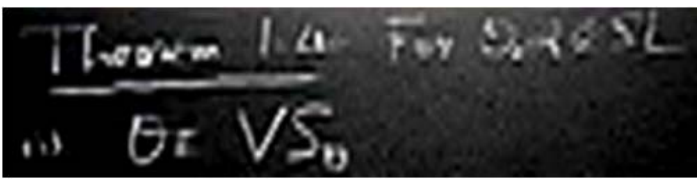

Theorem 1.4 For $\theta, \varphi \in \mathrm{SL}$

(i) $\theta \equiv \bigvee S_{\theta}$

Figure 1: The theorem to be proved

Having written down the theorem on the right board, the lecturer then 'talks-writes' the proof on the left board (Figure 2). 


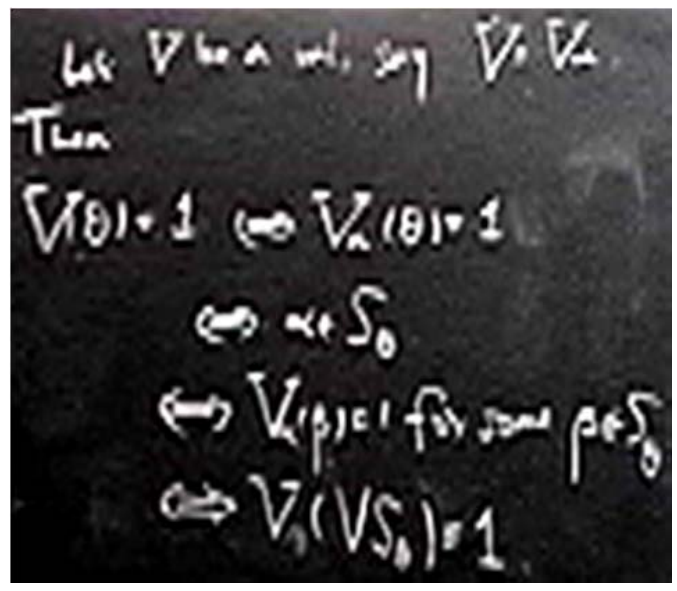

Let $V$ be a val. say $V=V_{\alpha}$

Then

$$
\begin{aligned}
V(\theta)=1 & \Leftrightarrow V_{\alpha}(\theta)=1 \\
& \Leftrightarrow \alpha \in S_{\theta} \\
& \Leftrightarrow V_{\alpha}(\beta)=1 \text { for some } \beta \in S_{\theta} \\
& \Leftrightarrow V\left(\bigvee S_{\theta}\right)=1
\end{aligned}
$$

\section{Figure 2: The finished proof}

In our view, the written theorem and proof on the blackboard are the clearest expression of what Hersh has in mind when he speaks of mathematics in the 'front' as 'formal, precise, ordered and abstract'. The finished proof has a formal character, a very clear structure, and consists predominantly of formulaic expressions stated in abstract symbols. Furthermore, there is nothing in the presentation of the theorem or proof that would be characterized as 'personal, controversial, [or] tentative'. However, the presentation of the theorem and proof only fits Hersh's picture of the 'front' in a very limited way. This is visible when we take a long look at what the lecturer is doing while writing. The lecturer is not silently writing down the proof on the blackboard, but rather is talking the students through the proof while writing it. ${ }^{\text {xi }}$ Figure 3 shows the lecturer at the beginning of the proof and Transcript 1 presents his accompanying talk. 


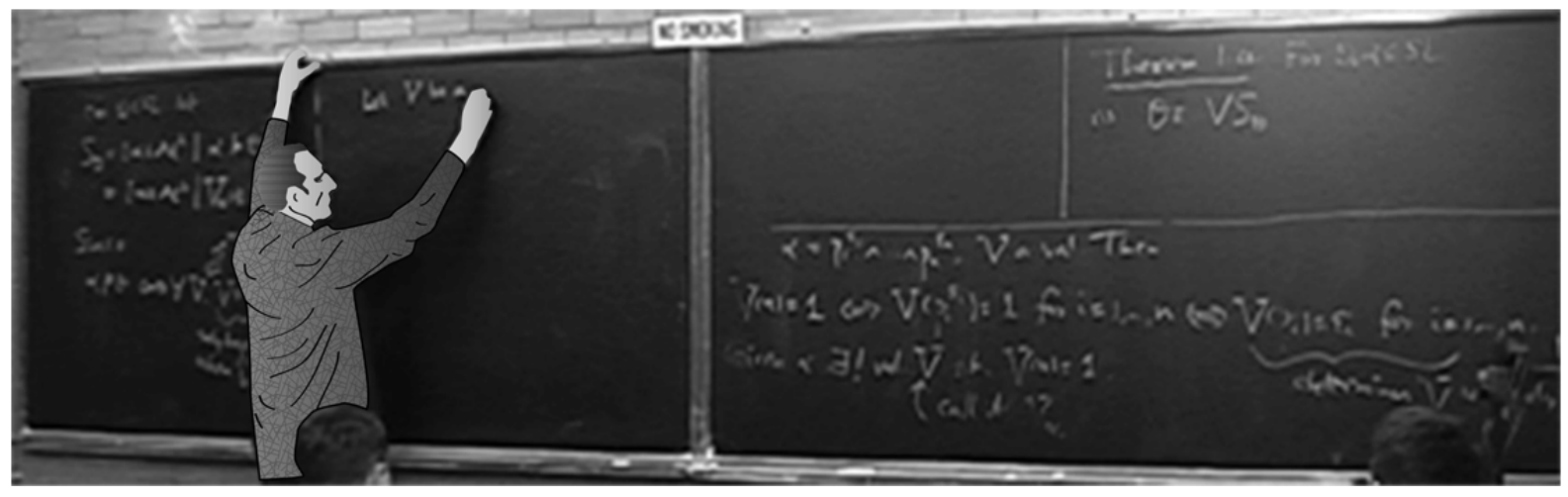

Figure 3: lecturer at the beginning of the proof ${ }^{\mathrm{xvii}}$

\section{Transcript 1}

I Okay.Well let's let vee be a valuation. Let's say- >look, we know every valuation is of the

2 form vee alpha for some atom alpha, so lets say vee equals vee alpha. It's a useful trick to do

3 it this way. Then vee of theta equals one, well, if and only if, cos that's the same thing as vee

4 alpha, if and only if vee alpha of theta equals one. If and only if, well that's the same as

5 saying alpha's in ess theta, isn't it? Cos here we are. Here's ess theta (up there), over here.

6 So that's exactly the same as saying that. That condition is saying the same as alpha is in ess

7 theta. Okay. And that's if and only if, now vee alpha of beta equals one, it's a funny way of

8 saying it but you can see for why in a minute, if and only if vee alpha of beta equals one for

9 some beta in ess theta. Well, let's just see why that is. Okay, well if alpha is in ess theta, well

10 then alpha's in ess theta here. We take the beta to be equal to alpha and vee alpha of alpha

II equals one. Okay, so that's true. So if alpha's in ess theta there is such a beta, namely alpha.

12 On the other hand, if alpha's not in ess theta, then any beta we choose in ess theta will not

13 be equal to alpha, so vee alpha of that atom will get value zero. Cos there's a unique atom

14 that it gives value one to, namely alpha. So this funny way of writing things here is okay. And

15 the reason for doing it like that is now, that's if and only if vee alpha of the disjunction of ess

16 theta equals one, right? Cos vee alpha of that disjunction will get value one just if vee alpha

17 of one of the disjuncts gets value one. In other words, vee alpha of one of the things in ess

18 theta is equal to one and that's just-, so vee alpha and vee are the same thing, so that's if and

19 only if vee of this equals one. Okay. So these two things theta and the disjunction of ess

20 theta are logically equivalent. That's why it's important. That's why, in a sense, theta can be

21 thought of as being made up of the atoms in ess theta. It's just, it's just logically equivalent to

22 the disjunction of those atoms. Furthermore:

It is true that in the talk accompanying the writing, the lecturer does not express anything that could be called his personal views of the theorem or proof, nor mention any controversies that may have arisen in the past, nor discuss the stages of uncertainty in developing the theorem and proofs. However, the lecturer does provide various elaborations, explanations, emphases, and reminders. For example, he: 
- reminds students of a previous result ('look, we know every valuation is of the form vee alpha for some atom alpha');

- highlights the importance of a particular step ('It's a useful trick to do it this way');

- $\quad$ points to a previous result (Figure 4);

- projects that an upcoming step is 'unusual' ('it's a funny way of saying it but you can see for why in a minute');

- provides a summary of what he has done so far amounts to mathematically ('That's why it's important. That's why, in a sense, theta can be thought of as being made up of the atoms in ess theta.').

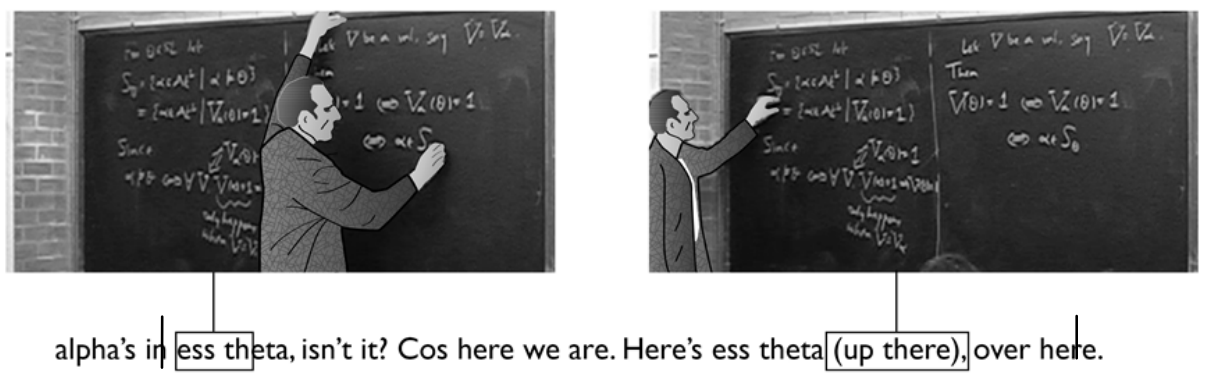

Figure 4: pointing to a previous result

When we look in detail at the way the lecturer presents the proof, we see that, although the written proof on the page or blackboard may have a 'formal, precise, ordered and abstract' character, the lecturer does not argue that understanding the proof is 'mechanical' or 'automatic'. As Davis and Hersh have noted, mathematicians (students and professionals) typically are not able to take in proofs by reading through them once at normal speed:

Why are textbook and monograph presentations of mathematics so difficult to follow? The layman might get the idea that a skilful mathematician can sight-read a page of mathematics in the way that Liszt sight-read a page of difficult piano music. This is rarely the case. The absorption of a page of mathematics on the part of the professional is often a slow, 
tedious, and painstaking process. (Davis and Hersh, 1981:

281)

In other words, although the lecturer presents a formal, deductive, abstract proof, he is not portraying mathematics (or mathematical reasoning) as monotonously formal, deductive, or abstract.

We would argue that the lecturer is predominantly concerned with outlining the various techniques and ways of working that are used not just in this proof, but in this branch of mathematics. For example, in marking the first step in this proof $\left(V=V_{\alpha}\right.$ for some atom $\alpha$ ) as 'a useful little trick', the lecturer lets students know that they could possibly use this in connection with other problems. In that sense, lectures in mathematics could be seen as an attempt to teach students how proving is done by showing what sorts of things count as proofs, what makes them successful as proofs, what techniques are employed in organising proofs, and so on.

Even this example of the 'technical' presentation of a theorem and proof thus only fits Hersh's picture of the 'front' in a very limited way. When we look at other remarks made by lecturers throughout these lectures, we find other aspects that are supposedly missing from the 'front'. Thus lecturers do, on occasion, acknowledge:

- that finding proofs is difficult (and in no way automatic or mechanical);

- that understanding proofs requires effort (and is not always easy);

- that theorems and proofs may have a history (that is, they may have been revised in light of counterexamples or mistakes);

- that mathematicians disagree about particular definitions.

These acknowledgements are made as low key, matter of course observations embedded in the lecture. They are not offered as unprecedented admissions that will deeply disturb the ideas the students attending the lecture might have had. For example, after giving a proof of a theorem in nonmonotonic logic (a relatively recent 
development in formal logic), the lecturer states that this proof is more difficult than a similar one in 'classical' logic:

\section{Transcript 2}

I Not quite such an obvious proof as it was for the sentential calculus, of course, where you

2 just, where you could really very often see, after a little bit of practice, you could see how

3 to produce the proof. In this subject, it's much more difficult to see how to do derivations

4 like this. Sometimes they require rather tricky sort of, tricky sort of steps.

The lecturer here explicitly formulates something that students will have encountered when tackling their weekly exercise sheets: it is sometimes difficult to find proofs.

Another way in which a lecturer may demonstrate that understanding the materials is difficult (and in no way automatic) is that on occasion he or she may do 'redundant' things. For example, having written a theorem in two parts, another lecturer immediately notes that part one would follow from part two. So why not just prove part two? Because the proof of the first part is, in the lecturer's opinion, easier to follow:

\section{$\underline{\text { Transcript } 3}$}

I But, in fact, you don't really need to prove the first one, cos it actually follows from the

2 second. However, l've stated them independently here, because it's actually instructive to go

3 through the proof of the first one first, because the second, the proof of the second is

4 slightly more complicated than the first, the proof of the first one. (Well it) makes it easier

5 to follow, I think, if you do them separately

The lecturer here states that understanding a proof is not always easy. However, this is not marked in any way as something that would be a surprise to students, indicating that the lecturer expects the students to accept this without additional comment.

It is true that, for the most part, historical remarks about the development of the field, earlier controversies, or open conjectures did not form part of these lectures.

Nevertheless, they were not completely absent. For example, another lecturer made the following remark about a theorem: 


\section{Transcript 4}

I Cox's theorem actually has a very long history. Part of the problem is that it is actually

2 quite difficult to state the theorem accurately, in a version so that it can actually be proved.

3 Cox and various successors produced a rather simple set of axioms, where the problem

4 was that they didn't actually quite prove what they purported to prove. There were

5 certain technical difficulties in actually proving the theorem. These were really only sorted

6 out by Jeff Paris here about ten years ago, who did finally prove a correct version of a

7 theorem that had been around for about fifty years. In fact, a lot of the time people didn't

8 even realise that the theorem was incorrectly stated.

Here the lecturer acknowledges (in the 'front') that mathematical publications contain faulty theorems and proofs and that spotting such mistakes is not easy, even for experienced specialists. ${ }^{\text {viii }}$

Lecturers may even mention disagreements, as is in the following example, in which a lecturer remarks that there are different (competing) views about the 'correct' way of formalizing 'belief':

\section{$\underline{\text { Transcript } 5}$}

I Okay. So we've proved some elementary things, which all follow from these two axioms.

2 Now having done this, let me sow some doubt in your mind. I will show you that in fact

3 there are other approaches which are possible. Not everybody agrees that belief should

4 actually satisfy these axioms, although this is certainly the most classical approach to

5 uncertainty, or reasoning under uncertainty. One of the, one of the things which is actually

6 being abandoned here, if abandoned is the right word, is the idea that a belief function

7 should be truth functional.

It is true that talk about controversies or disagreements was rare. However, in our view, the 'absence' of such talk is not a form of misrepresentation of mathematics on the part of lecturers, but rather a reflection of the fact that what is communicated in lectures and textbooks is predominantly part of the 'archive' of mathematics (cf., Wittgenstein, 1976: 105-107), which is treated as (currently) settled and, indeed, definitive of the nature of the field within which the course is sited. Furthermore, while controversies and conjectures may be relatively absent from mathematical lectures, they are certainly present in another part of the 'front' of mathematics, namely conference presentations, where presenters do report open questions and conjectures. $^{\text {xix }}$

In sum, when we look at the variety of remarks made in lectures, we find that lectures only superficially fit Hersh's picture of the 'front'. Firstly, although the lecturer 
presents the theorem and proof in a 'formal, precise, ordered and abstract' manner, the lecturer does not communicate that understanding the proof is in any way a mechanical or automatic process (otherwise, why would the lecturer spend so much effort at making visible how the proof 'works'?). Secondly, although remarks about the development of the field, earlier disagreements or problems, and open conjectures are rare, they are not completely absent and are furthermore presented as commonplaces (and not as destabilising students' understanding of the nature of mathematics). Thirdly, the reason for this relative absence is in our view not an attempt to make mathematics appear more certain than it 'really is', but a consequence of the instructional emphasis on explaining the technical details of the theorem and proof, and the implied relevancies of such an emphasis.

None of this is to say that there might not be good arguments for changing the style of presenting mathematics. Mathematicians do, on occasion, have discussions about the 'best' way of presenting mathematics. For example, some mathematicians do not like the current 'formalist' way of presenting mathematics. ${ }^{\mathrm{xx}}$ However, it should be noted that a succinct presentation style does not have only disadvantages. Heintz (2000: 123) points out that the style of mathematical texts has not just 'strategic', but also 'communicative', functions. If all contingencies, uncertainties, false avenues, etc. were displayed, mathematical papers would no longer be readable. In other words, the style of writing facilitates mathematical communication rather excluding information essential to understanding the mathematics. ${ }^{x x i}$

It may be that a different presentation style would bring educational benefits, i.e., remove 'learning obstacles' (Ernest, 2008: 67). This argument is often based on the view that neither the lecturer nor the students are in any way engaged in mathematical discovery during these lectures. If all that students do is take up existing proofs, how are they ever to learn how to create proofs themselves? However, it is important to note that studying existing proofs is not something that is completely discontinuous with coming up with new proofs. As Davis and Hersh acknowledge, professional mathematicians also need to study proofs to understand what they are saying and how they work (in other words, studying proofs is not something that only outsiders do). Furthermore, as Davis and Hersh also observe, 
studying proofs in this fashion is one way for students to become familiar with what is involved in the creation of new mathematics:

Proof, in its best instances, increases understanding by revealing the heart of the matter. Proof suggests new mathematics. The novice who studies proofs gets closer to the creation of new mathematics. Proof is mathematical power, the electric voltage of the subject which vitalizes the static assertions of the theorems. (Davis and Hersh, 1981: 151)

In other words, understanding how to do proving on your own behalf is the reciprocal of understanding how proving has been done, which equates to understanding of what proving is. Students who study proofs are coming to understand what, in an important sense, mathematics is, namely, accumulated collections of proofs. By learning and understanding the proofs, they are familiarising themselves with a major resource for any innovative mathematical work of their own; namely, the knowledge of what has already been proved and of the forms and techniques legitimately used in those proofs.

What we are sceptical about is Hersh's claim that a different way of presenting mathematics would lead to the disappearance of the various myths about mathematics. We have argued that the traditional 'Euclid myth' picture of mathematics does not directly emerge from the current style of presenting mathematics. If we are right, then it does not follow that a new way of presenting mathematics would do away with the mythical ideas. Establishing the in-principle point that mathematicians sometimes make errors requires only one or two examples, but it is not clear what a detailed history of each proof's formation would actually teach.

\section{Supervision meetings: the 'back'}

In a second study, we attended for almost a year the weekly meetings between a supervisor and his doctoral students. These meetings are one example of mathematics in the 'back', since we encounter mathematics-in-the-making rather than finished mathematics. The style of discussion between supervisor and doctoral students is very different from that found in the lecture and could, without close inspection, easily be characterized as 'fragmentary, informal, intuitive, tentative'. 
Furthermore, supervisors and doctoral students frequently 'try this or that' and 'say "maybe" or "it looks like"'. We will argue that this neither shows that the 'back' is permeated with 'uncertainty', nor that the mathematical resources in use are being treated as less dependable than they are presented as being in mathematical publications.

In the meetings with a first-year doctoral student doing research in probability logic, the supervisor and student initially spent a lot of time trying to find a 'doable' problem the student could work on (cf., Fujimura, 1987; Delamont et al., 2000). They finally focussed on the problem of generalizing a theorem that the supervisor had previously proven and published (on a new way to draw inferences from an inconsistent set).

The following episode, taken from a meeting a few months after the start of the student's doctorate, is fairly typical. Prior to the meeting, the student has handed in a sketch of a proof, which the supervisor has read. At the beginning of the meeting, the supervisor tells the student that he does not think that the sketch is currently detailed enough and that he is rather doubtful that the student will be able to prove the result the student claims to prove (that is, the supervisor finds the idea of being able to prove this result mathematically implausible). In response, the student goes to the blackboard and goes through his idea in more detail (Figure 5).

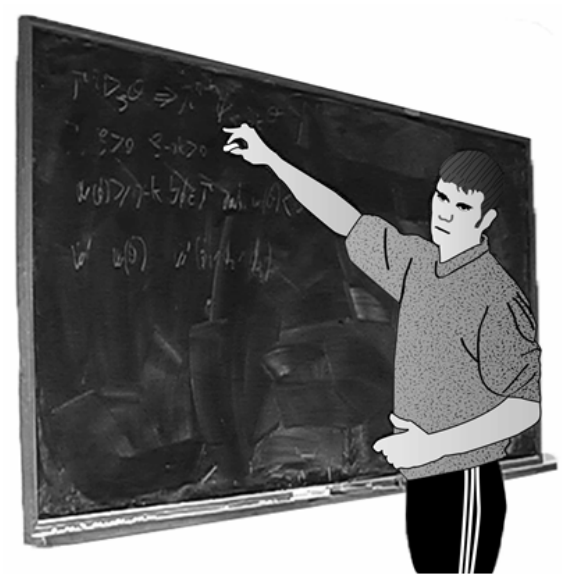

Figure 5: student demonstrating his idea at the blackboard

Listening to the student, the supervisor is not able to 'see' the proof. However, neither is the supervisor able to see any 'obvious' snags. In order to get a better 
understanding, the supervisor in turn goes to the blackboard and attempts to work through the student's proposed idea himself (Figure 6). While doing so, the supervisor frequently checks with the student whether he has understood him correctly (e.g., by asking 'and what you wanna do is ...?').

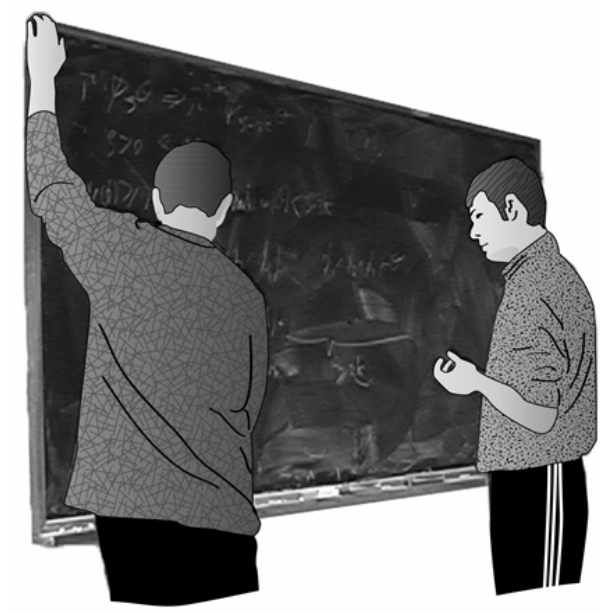

Figure 6: supervisor working through the student's idea

The supervisor (SU) asks the student (ST) a variety of questions, 'interrogating' the student - and thereby the student's proposed idea - in the hope either of pinpointing an obvious 'fault' or confirming that the student's idea 'really' works. The following is a good example:

\section{Transcript 6.1}

I SU: What about this one? What about this one here?

2 ST: I left it, I wouldn't move it. I move only the ones with theta.

3 SU: Only the ones with theta in you gonna move?

4 ST: Yeah.

5 SU: So how much? You don't know how much you move. I mean you're moving this, but

6 there might be lots of probability in these things.

7 ST: Yeah. And what l'm saying is that at least there is two kappa. Hence if there's two

$8 \quad$ kappa at least, I know that I can transfer two kappa again to this atom. And then find

9 a contradiction. That was the idea. (inaudible)

I0 SU: Right.

Although we cannot give all the necessary background information of what is going on in this particular case, we think it is visible that the supervisor is asking 'probing' questions in order to find out, in what has sketched on the blackboard, whether something might be missing or whether one part of the presented argument might 
contradict another one. The student gives defensive responses that the supervisor cannot decisively reject, but that do not completely satisfy him either. In fact, even the student is not completely sure that his idea will work:

\section{Transcript 6.2}

I ST: The thing is, sometimes I make very silly mistakes. So maybe I'm missing out on

2 something, that could happen. But the way it looks. That's why I said 'it's obvious' ((laughs)), the way it looks.

In response, the supervisor explains why he does not think that the student can prove the result that he claims. He thinks that the student is asserting a much stronger result than anticipated:

\section{Transcript 6.3}

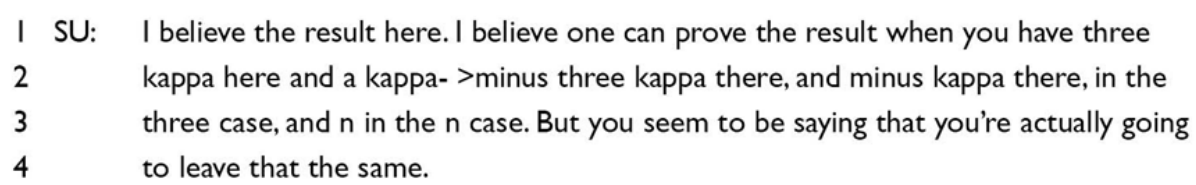

The supervisor is saying that the arguments put forward by the student would seem to allow proving a much stronger result (which does not depend on $n$ - the size of the set $\Gamma$ ) than he anticipates. As noted, however, the supervisor is not able to find either an obvious flaw in the student's argumentation or (within the limits of this meeting) a quick counter-example that would show that the result that the student is seemingly proving is false. The difference between the supervisor and student is not resolved in this meeting and the episode ends with the supervisor advising the student: 'well I think you should write that one out in detail'.

It is clear that this is a different kind of activity from the mathematical lecture, where there was indeed an 'air of certainty': the lecturer knew that all the theorems had proofs and if for some reason he forgot how to prove a particular theorem he could simply look it up. In contrast, in this meeting there is an 'air of uncertainty': the doctoral student is not completely sure that his idea will work, but neither is the supervisor absolutely certain that the student will be unable to prove the stronger result. 
Hersh characterizes the 'back' as 'fragmentary, informal, intuitive, tentative', and this excerpt would seem to fit that picture. Rather than working on a 'complete' proof, both supervisor and student are working on a more or less worked out 'idea'. Both are currently working at the level of guesses and 'gut feelings' about the value of that idea and both are somewhat tentative: the idea looks good to the student but he acknowledges that he might be overlooking a problem ('maybe I'm missing out on something'); the supervisor remains sceptical but cannot find an obvious fault in the student's arguments. The supervisor cannot 'check' the proof in detail, because the relevant detail has not yet been worked out and written down. The supervisor's questions to the student thus attempt to solicit more strategic detail, since the student's hope to deliver the proof depends upon its detailed realisation.

The thing that strikes us the most about this supervision meeting is the following: the student has given a rough outline idea of a proof (van Bendegem, 1988) - and an idea by its very nature is only partially worked out. However, the idea is offered as a preliminary move - as only anticipating a conclusive spelling out. Thus, both supervisor and student are assuming that having an 'idea' is not enough and that, in this case at least, the partial presentation is not enough to make the idea firmly convincing - that the idea can work is, for the supervisor, questionable on the face of it, requiring that the student establish that it can stand up by working it out in full. What the supervisor and student are doing is directed toward, and compared to, standards that call for something 'formal, precise, ordered and abstract', and they measure their current moves against the possibility of turning them into just that. As Coleman (2009: 30) notes: 'Although proofs, or more often their leading ideas, are frequently conveyed by word of mouth, only written proofs count as establishing a theorem.'

This nicely shows that the 'front' and the 'back' are not in opposition. It is not as though the work in the 'back' goes on without a concern for the formation of a tight and tidy logical sequence which is later added only for purposes of presentation. The demands of tight, tidy and logically sequenced construction are very much at stake in the work in hand. 'Informal, tentative, and intuitive' may characterise the way in which the supervisor and student are testing out the idea, but this is because they are anticipating work that needs to be done. This does not suggest that they are 
using different (more relaxed, more informal) standards of proof than would apply to a published proof. The difference between the 'front' and the 'back' then is not between two kinds of proof, one 'formal, precise, ordered and abstract' and the other 'fragmentary, informal, intuitive, and tentative'. Rather, it is a difference between different stages: of working with an incomplete idea of a possible proof as opposed to presenting a (presumably) complete, thoroughly worked-out-a-proof.

It is important to note that not mentioning something is not the same as concealing it. In our view, the temptation to think that a mathematical paper is a misrepresentation of what happens in the 'back' is based on a view that treats the paper as a description (in the form of sociological or historical report) of the discovery processes, rather than as a presentation of the relevantly interrelated mathematical matters. A published mathematical proof does not give an 'accurate' description of how the theorem was worked out in the first place, but neither does it give an 'inaccurate' one, since it does not purport to give any such a description. The idea that the form of a finalised proof provides a description of the mathematical reasoning that produced it is about as wise as thinking that Hollywood blockbusters ought to be viewed as documentaries about their own production. The published mathematical paper provides a statement of the proof that has been (successfully) worked out, not a description of how its author(s) put it together and prepared it for publication. The paper delivers the results of their efforts, not a record of the efforts themselves.

Hersh argues that non-mathematicians are not familiar with what happens in the 'back' and we would agree with that. Not many people will have seen or experienced exchanges such as the one between the supervisor and his doctoral student. Hersh is right that these are not widely reported in publications or popular media. However, Hersh's central claim is based on the view that exposure to the 'back' would allow 'to develop a less naive, more sophisticated attitude towards the myths of the profession' (p. 132). In contrast, we wonder whether such exposure would come as a much of a shock.

If we take another look at Goffman's frontstage/backstage metaphor with respect to restaurants, it is certainly the case that there is a separation between the quiet, 
orderly 'front' dining area and the messy, chaotic, smelly 'back' kitchen. Furthermore, the 'back' of establishments is frequently 'concealed' from customers, but are they thereby 'misled', or, as Hersh puts it himself, is it more that they are 'enthralled'? In other words, is the separation between 'front' and 'back' an attempt at deceiving the customers or a way of maximising their enjoyment? Hersh himself notes that the 'myth, in many cases, adds to the customer's enjoyment of the performance', which is a far cry from saying that the myth is created in order to boost the status of, e.g., restaurants. What would the reaction of customers be if they were 'exposed' to the 'backs' of restaurants? Would it be shock and disillusion? These days some restaurants include the 'back' in the 'front' by having a large window in the dining area into the kitchen (making available in the 'front' what is happening in the 'back'). It could be said that such displays change the experience of going to restaurants, but we wonder whether it is best characterised as a change from a 'misleading' to a 'faithful' picture of the workings of restaurants.

Goffman illustrates his general thesis with examples, in which 'giving off' back region information to the audience would discredit the public performance, in particular, in the case of confidence tricksters. However, it is not Goffman's thesis that the division always plays a falsifying role, rather that it often plays a functional one: what goes on out of sight of the (actual or potential audience) enables the public performance to be successful, organises the performers so they know what they are supposed to do when they are 'on' (the weeks of rehearsal for a show), or provides temporary opportunities to ease any rigorous demands on the performance (such as when taking a coffee break from the strain of keeping up a polite demeanour to rude, aggressive, and annoying customers). Hersh does recognise that the back region facilitates realisation of a quality performance, but seems mainly to imply that what goes on in that region would discredit the public performance, at least with respect to the 'certainty' of mathematics. It is as if access to information about mathematician's prepublication work would be what Goffman calls an 'inopportune intrusion':

When an outsider accidentally enters a region in which a performance is being given, or when a member of the audience inadvertently enters the backstage, the intruder is likely to catch those present flagrante delicto. Through no one's intention, the persons present in the region may find that they have patently

Greiffenhagen, C. and W. Sharrock (2011). Does mathematics look certain in the front, but fallible in the back? Social Studies of Science 41 (6), 839-866. 
been witnessed in activity that is quite incompatible with the impression that they are, for wider social reasons, under

obligation to maintain to the intruder. (Goffman, 1956: 132)

What, though, would count as a case of mathematical flagrante delicto? Hersh thinks that the fact that mathematical investigators speak provisionally amongst themselves is at odds with the image of relentless certainty. However, the questioning, tentative, uncertain tone of the supervisory exchange does not betray any lack of confidence in the mathematics they are using, deriving more from the fact that they have selected a project that they should be able to do, but that will nonetheless be a challenge for them. Though there are anticipations of how things might turn out, of what routes might engender a proof, those anticipations are not assured of fulfilment, for it is only through doing the work of forming (parts of) the proof in detail that it will be found out whether those anticipations can be fulfilled. From the fact that, by the time they have got something to publish, they will be pretty certain of what they have done it would be just gratuitous to construe them as implying that they were always equally certain.

Goffman also suggests that the front/back separation allows performers to talk about the audience in a derogatory manner in the 'back':

When the members of a team go backstage where the audience cannot see or hear them, they very regularly derogate the audience in a way that is inconsistent with the face-to-face treatment that is given to the audience. In service trades, for example, customers who are treated respectfully during the performance are often ridiculed, gossiped about, caricatured, cursed, and criticized when the performers are backstage .... (Goffman, 1956: 108)

However, how is this applicable to mathematics? What we have observed so far 'behind closed doors' does not seem to point to mathematicians being 'two-faced', holding one view of mathematics in presentation and publications, while secretly having a different view of mathematics (and a disdain for the 'outsiders' who take the public image as face value). We would argue that their view of mathematics is fairly consistent, both at the 'front' and at the 'back'. 


\section{Conclusion}

In this paper we have engaged with the question of whether the form of presenting mathematics (in lectures or textbooks) explains the existence of various myths about it. We have argued that the different exposures to the 'front' (by outsiders) and to the 'back' (by insiders) is not responsible for the myths, not least because some of the major exponents of myths about mathematics are themselves high achieving mathematicians, possessing a deep familiarity with practices in the 'back' region.

In our view, the idea that the form of mathematical publications encourages myths about certainty results from drawing an invalid inference from a plain fact, which is that historical commentary and documentation of 'the context of discovery' is almost entirely absent from mathematical lectures and papers. This absence might indicate that the published matter has no prior history, and that the deductive structure of the exposited proof is a description of the discovery process. However, as we have argued, rather being 'misrepresentations' of the nature of mathematics, these aspects of proofs are expressions of the interests of mathematicians in the technical details of theorems and proofs.

The idea that the public mathematical record hides the fallibility of mathematics is based upon too narrow a consideration, concentrating only on the format of the single mathematical paper and focussing, for example, only on the fact that the individual paper setting out a theorem and proof usually does not also describe the difficulties and failings that may have featured in their creation. Such a 'failure' to describe should not be taken to suggest that there were no difficulties. Such a 'failure' is a poor basis for inferring that mathematics hides its fallibility, since a survey of a relatively few mathematical papers is likely to show that mathematicians are aware of, acknowledge, and routinely publicise, errors in their own or other mathematicians' papers. ${ }^{x x i i}$

The 'myth of certainty' about mathematics seems to survive in face of the 'loss of certainty' precipitated by such world-renowned developments as non-Euclidean geometries and Gödel's Incompleteness Theorems. This, in our view, shows that the various myths of mathematics do not originate in the differences between mathematics in the 'front' and the 'back'. While the myth of certainty does need 
dispelling, we think that the front/back contrast risks creating a counter-myth, the 'myth of uncertainty'.

Lakatos is often cited for replacing the myth of certainty with a fallibilist view of mathematics, but his ideas are completely independent of the 'front/'back' contrast, since his study draws upon published articles (entirely from the 'front'). Furthermore, Lakatos' fallibilism says nothing about how seriously, in what ways, and with what consequences existing mathematics may be 'in error'. ${ }^{x i i i}$ His argument is about the logical status of mathematical claims and his 'fallibilism' holds that mathematical statements do not express absolute certainties. Lakatos argues that mathematical claims are conjectures, but this has to be understood in relation to Popper's sense of conjectures, not in the mathematical sense of an 'open question' (see endnote xix). Mathematical statements are conjectures in the sense that, for any mathematical proposition the possibility of a counter example cannot logically be excluded. Lakatos' argument applies to mathematical statements (in the 'front') and he agrees that any conception of these as unquestionably true is simply a misunderstanding of the kinds of statements they are.

We would not like our arguments against the way in which the front/back distinction has been applied to mathematics to be taken as implying that there is no point or value in looking 'behind the scenes' of mathematical practice, not least because this is what we ourselves have been doing. We have only argued that it should not be expected that increased familiarity with what goes on 'in the mathematical back' will lead to any significant revision of understanding of what is on show 'out front'. In our examples, we have tried to show that 'working behind the scenes' in mathematics does not involve being exposed to a kind of reasoning that conflicts with the kind that appears 'up front'. The only difference is, of course, that one is exposed to as-yetstill-exploratory reasoning, rather than provably successful examples, which is only a restatement of the difference between currently unfinished and finished work.

\section{Acknowledgements}

We are immensely grateful to the lecturers and students who allowed us to observe and record the lectures and supervision meetings and who more generally helped with the research. An earlier version of this paper was presented at the Conference 
Foundations of the Formal Sciences VII: Bringing together Philosophy and Sociology of Science (Brussels, Belgium, October 21-24, 2008). We would like to thank Mike Lynch and the anonymous reviewers for comments on an earlier draft. Christian Greiffenhagen gratefully acknowledges the support through a British Academy Postdoctoral Fellowship and a Simon Research Fellowship (funded through an endowment made to the University of Manchester).

\section{Notes}

'As Schickore (2008: 324) points out, this contrast has a long history that goes back at least to Reichenbach's (1938) distinction between 'the context of discovery' and 'the context of justification'.

ii This way of phrasing things raises questions about the kind of writing in question, in particular, its intended audience. We address this ambiguity more explicitly below.

iii The argument that scientific papers misrepresent or distort how science is actually done has been made, inter alia, by Mulkay (1976: 642), Latour and Woolgar (1979: 28), Gilbert and Mulkay (1980: 277), Knorr-Cetina (1981: 94-95), and Delamont and Atkinson (2001: 102-103). For a different way of dealing with the contrast see Lynch et al. (1983: 210) and Lynch (1985: 150-154).

${ }^{i v}$ For example, Davis and Hersh (1981: 325), Watson (1990: 283), Hersh (1991: 129), and Dowling (2001: 21).

${ }^{\vee}$ For example, Borba and Skovsmose (1997), Ernest (1991: 260; 1998: xii), and Henrion (1997: 255).

vi See Davis and Hersh (1981: 151), Thurston (1994: 163), or Weber (2004: 116). 
vii Thus Rota (1991: 172): 'Mathematicians take mischievous pleasure in faking the arbitrariness of definition. In actual fact, no mathematical definition is arbitrary. The theorems of mathematicians motivate the definitions as much as the definitions motivate the theorems. A good definition is "justified" by the theorems one can prove with it, just like the proof of a theorem is "justified" by appealing to a previously given definition. There is thus, a hidden circularity in formal mathematical exposition. The theorems are proved starting with definitions, but the definitions themselves are motivated by the theorems that we have previously decided ought to be right.'

viii See also Borasi (1992: 161), Crawford et al. (1996: 466), Kemeny (2003: 1549), Livingston (2006: 60), and Powell and Brantlinger (2008: 428).

ix The article appeared first in Eureka, the journal of the Cambridge University Mathematical Society (Hersh, 1988), and was then reprinted in the journal Synthese (Hersh, 1991). An edited version forms part of Hersh's book What Is Mathematics, Really? (Hersh, 1997: 35-39).

${ }^{x}$ Hersh assumes this, but others suppose that the mathematicians themselves may have swallowed the myths or ideology about their own discipline.

${ }^{x i}$ Conversely, it is sometimes argued that the way that mathematics is presented in the 'front' is the reason that so many people do not enjoy mathematics.

xii See also, for example, Davis and Hersh (1981: 36), Morgan (1998: 11), and Burton and Morgan (2000: 435).

xiii According to David Bloor $(1976,1994)$ many people (falsely) believe in the universality of mathematics, assuming for example that $2+2$ must equal 4 , and therefore do not realize the conventional character of mathematics (for example, the use of a decimal rather than binary notation). The aim of Bloor's sociology of mathematics is thus to demonstrate that mathematical propositions 'could have been otherwise' and thereby to show that no one is compelled to accept these 
propositions on the grounds that they could not possibly be otherwise (these views are questioned in Greiffenhagen and Sharrock, 2009a,b).

xiv See, for example, Bloor (1976, Chapter 7), Davis and Hersh (1981, Chapter 7), and Ernest (1998, Chapter 4).

${ }^{x v}$ This theorem states that for all sentences theta of the language SL, the sentence theta is logically equivalent to disjunction of all the sentences in the set $S_{\theta}$.

xvi The exact relationship between what a lecturer says and writes on the board is rather intricate and would form an interesting topic of investigation in its own right.

xvii Many thanks to Jonas Ivarsson (University of Gothenburg) for help in the preparation of these images (see, for example, Ivarsson, 2010).

xviii As Lakatos (1976: 4, n. 1) remarks: 'But often the checking of an ordinary (informal) proof is a very delicate enterprise, and to hit on a "mistake" requires as much insight and luck as to hit on a proof: the discovery of "mistakes" in informal proofs may sometimes take decades - if not centuries.'

xix An illustration of this is provided by Higham (1998: 17): 'A fifth kind of statement used in mathematical writing is a conjecture - a statement that the author thinks may be true but has been unable to prove or disprove. ... A famous computer scientist (let us call him Alpha) joked in a talk "This is the Alpha and Beta conjecture. If it turns out to be false I would like it to be known as Beta's conjecture." However, it is not necessarily a bad thing to make a conjecture that is later disproved: identifying the question that the conjecture aims to answer can be an important contribution.'

${ }^{x x}$ Burton and Morgan (2000: 449), for example, quote a mathematician who calls for changes: 'I get annoyed with some of my collaborators and a lot of the papers I am sent, which are definition, theorem, lemma, proof. That seems to me to be appallingly bad. It is the sort of thing that no one is ever going to want to read. I think 
it is important to grab the reader from the opening sentence. Not "Let A be a class of algebras such that ..." Change it to "This paper opens a new chapter in duality theory."'

${ }^{x \times i}$ A similar remark is made by the mathematician Paul Halmos (1970: 127): 'The discoverer of an idea, who may of course be the same as its expositor, stumbled on it helter-skelter, inefficiently, almost at random. If there were no way to trip to consolidate, and to rearrange the discovery, every student would have to recapitulate it, there would be no advantage to be gained from standing "on the shoulder of giants", and there would never be time to learn something new that the previous generation did not know.'

xxii Fisher (1973: 1101), in a study of the various attempts to solve the Poincaré conjecture, reports: 'Soon after the statement of the conjecture was published, a well-known mathematician published a proof of it. He immediately uncovered an error in his demonstration and in the next issue of the journal pointed out his mistakes.' Similarly, Brown (2009: 232) states that mathematicians are aware of mistakes: 'Everyone - especially a working mathematician - will admit that the literature (including at least two of this writer's own papers) contains mistakes.'

xxiii As Koetsier (1991: 45) pointedly asks: 'If mathematical knowledge is fallible, how fallible is it?' 


\section{References}

Aspray W and Kitcher P (eds) (1988) History and Philosophy of Modern

Mathematics. Minneapolis, MN: University of Minnesota Press.

Bloor D (1976) Knowledge and Social Imagery. London: Routledge \& Kegan Paul.

Bloor D (1994) What can the sociologist of knowledge say about $2+2=4$ ? In:

Ernest P (ed) Mathematics, Education and Philosophy: An International

Perspective. London: Falmer, 21-32.

Borasi R (1992) Learning Mathematics Through Inquiry. Portsmouth, NH:

Heinemann.

Borba M C and Skovsmose O (1997) The ideology of certainty in mathematics education. For the Learning of Mathematics 17(3): 17-23.

Borel A (1994) On the place of mathematics in culture. In: Artin M, Kraft $\mathrm{H}$ and Remmert R (eds) Duration and Change: Fifty Years at Oberwolfach. Berlin: Springer, 139-158.

Brown R C (2009) Are Science And Mathematics Socially Constructed? A

Mathematician Encounters Postmodern Interpretations of Science. Singapore:

World Scientific Publishing.

Burton L and Morgan C (2000) Mathematicians writing. Journal for Research in Mathematics Education 31(4): 429-453.

Campbell D M (1976) The Whole Craft of Number. Boston: Prindle, Weber \& Schmidt.

Coleman E (2009) The surveyability of long proofs. Foundations of Science 14(1-2): 27-43.

Crawford K, Gordon S, Nicholas J, and Prosser M (1998) Qualitatively different experiences of learning mathematics at university. Learning and Instruction 8(5): 455-468.

Davis P J and Hersh R (1981) The Mathematical Experience. Boston: Birkhäuser.

Delamont S and Atkinson P (2001) Doctoring uncertainty: Mastering craft knowledge. Social Studies of Science 31(1): 87-107.

Delamont S, Atkinson P, and Parry O (2000) The Doctoral Experience: Success and Failure in Graduate School. London: Falmer.

Dowling $P$ (2001) Mathematics education in late modernity: Beyond myths and fragmentation. In: Atweh B, Forgasz H, and Nebres B (eds) Sociocultural Research on Mathematics Education: An International Perspective. Mahwah, NJ: Lawrence Erlbaum, 18-36.

Echeverria J, Ibarra A, and Mormann T (eds) (1992) The Space of Mathematics: Philosophical, Epistemological and Historical Explorations. Berlin: De Gruyter.

Ernest P (1991) The Philosophy of Mathematics Education. London: Falmer.

Ernest P (1998) Social Constructivism as a Philosophy of Mathematics. Albany, NY: State University of New York Press.

Greiffenhagen, C. and W. Sharrock (2011). Does mathematics look certain in the front, but fallible in the back? Social Studies of Science 41 (6), 839-866. 
Ernest P (2008) Opening the mathematics text: what does it say? In: de Freitas $E$ and Nolan K (eds) Opening the Research Text: Critical Insights and In(ter)ventions into Mathematics Education. Dordrecht: Springer, 65-80.

Fisher C S (1973) Some social characteristics of mathematicians and their work. American Journal of Sociology 78(5): 1094-1118.

Fujimura J H (1987) Constructing 'do-able' problems in cancer research: Articulating alignment. Social Studies of Science 17(2): 257-293.

Gilbert G N and Mulkay M (1980) Contexts of scientific discourse: Social accounting in experimental papers. In: Knorr K D, Krohn R, and Whitley R (eds) The Social Process of Scientific Investigation. Dordrecht: D. Reidel, 269-294.

Gillies G (ed) (1992) Revolutions in Mathematics. Oxford: Oxford University Press.

Goffman E (1956). The Presentation of Self in Everyday Life. Edinburgh: University of Edinburgh Social Sciences Research Centre.

Greiffenhagen C and Sharrock W (2009a) Two concepts of attachment to rules. Journal of Classical Sociology 9(4): 405-427.

Greiffenhagen C and Sharrock W (2009b). Mathematical equations as Durkheimian social facts? In: Cooper G, King A, and Rettie R (eds.) Sociological Objects: Reconfigurations of Social Theory. Aldershot: Ashgate, 119-135.

Halmos P R (1970) How to write mathematics. L'Enseignement Mathématique 16: 123-152.

Heintz B (2000) Die Innenwelt der Mathematik: Zur Kultur und Praxis einer beweisenden Disziplin. Wien: Springer.

Heintz B (2003) When is a proof a proof? Social Studies of Science 33(6): 929-943.

Henrion C (1997) The quest for certain and eternal knowledge. In: Henrion C, Women in Mathematics: The Addition of Difference. Bloomington, IN: Indiana University Press, 234-262

Hersh R (1988) Mathematics has a front and a back. Eureka 48: 27-31.

Hersh R (1991) Mathematics has a front and a back. Synthese 88(2): 127-133.

Hersh R (1997) What is Mathematics, Really? Oxford: Oxford University Press.

Hersh R (ed) (2005) 18 Unconventional Essays on the Nature of Mathematics.

Berlin: Springer.

Higham N J (1998) Handbook of Writing for the Mathematical Sciences, 2nd ed. Philadelphia, PA: Society for Industrial and Applied Mathematics.

Holmes F L (1987) Scientific writing and scientific discovery. Isis 78(2): 220-235.

Ivarsson J (2010) Developing the construction sight: Architectural education and technological change. Visual Communication 9(2): 171-191.

Kemeny V (2003) Geometry. In: Guthrie J W (ed) Encyclopaedia of Education, $2^{\text {nd }}$ ed., Volume 5. New York: Macmillan, 1548-1550.

Kitcher P (1983) The Nature of Mathematical Knowledge. Oxford: Oxford University Press.

Kline M (1980) Mathematics: The Loss Of Certainty. Oxford: Oxford University Press.

Greiffenhagen, C. and W. Sharrock (2011). Does mathematics look certain in the front, but fallible in the back? Social Studies of Science 41 (6), 839-866. 
Knorr-Cetina K (1981) The Manufacture of Knowledge: An Essay on the

Constructivist and Contextual Nature of Science. Oxford: Pergamon.

Koetsier T (1991) Lakatos' Philosophy Of Mathematics: A Historical Approach.

Amsterdam: North-Holland.

Krantz S G (1999) How to Teach Mathematics, $2^{\text {nd }}$ ed. Providence, RI: American Mathematical Society.

Lakatos I (1976) Proofs and Refutations: The Logic of Mathematical Discovery.

Cambridge: Cambridge University Press.

Latour B (1987) Science in Action. Cambridge, MA: Harvard University Press.

Latour B and Woolgar S (1979) Laboratory Life: The Social Construction of Scientific

Facts. London and Beverly Hills: Sage.

Lave J (1988) Cognition in Practice: Mind, Mathematics, and Culture in Everyday

Life. Cambridge: Cambridge University Press.

Livingston E (1986) The Ethnomethodological Foundations of Mathematics. London:

Routledge \& Kegan Paul.

Livingston E (1999) Cultures of proving. Social Studies of Science 29(6): 867-888.

Livingston E (2006) The context of proving. Social Studies of Science 36(1): 39-68.

Lynch M (1985) Art and Artifact in Laboratory Science: A Study of Shop Work and

Shop Talk in a Research Laboratory. London: Routledge \& Kegan Paul.

Lynch M, Livingston E, and Garfinkel H (1983) Temporal order in laboratory work. In:

Knorr-Cetina K D and Mulkay M (eds) Science Observed: Perspectives on the

Social Study of Science. London: Sage, 205-238.

MacKenzie D (1993) Negotiating arithmetic, constructing proof: The sociology of mathematics and information technology. Social Studies of Science 23(1): 37-65.

MacKenzie D (1999) Slaying the Kraken: The sociohistory of a mathematical proof.

Social Studies of Science 29(1): 7-60.

MacKenzie D (2001) Mechanizing Proof: Computing, Risk, and Trust. Cambridge, MA: MIT Press.

Medawar P B (1963) Is the scientific paper a fraud? The Listener 70 (12 September): 377-378.

Merz M and Knorr-Cetina K (1997) Deconstruction in a 'thinking' science: Theoretical physicists at work. Social Studies of Science 27(1): 73-111.

Morgan C (1998) Writing Mathematically: The Discourse of Investigation. London:

Falmer.

Mulkay M (1976) Norms and ideology in science. Social Science Information 15(4/5): 637-656.

Netz R (1999) The Shaping of Deduction in Greek Mathematics: A Study in

Cognitive History. Cambridge: Cambridge University Press.

Pólya G (1957[1945]). How to Solve It: A New Aspect of Mathematical Method, $2^{\text {nd }}$ ed. Princeton: Princeton University Press.

Greiffenhagen, C. and W. Sharrock (2011). Does mathematics look certain in the front, but fallible in the back? Social Studies of Science 41 (6), 839-866. 
Pólya G (1954) Mathematics and Plausible Reasoning. Volume 1, Induction and Analogy in Mathematics. Volume 2, Patterns of Plausible Inference. Princeton, NJ: Princeton University Press.

Pólya G (1981[1962, 1965]). Mathematical Discovery: On Understanding, Learning, and Teaching Problem Solving, Combined Edition. New York: John Wiley \& Sons.

Powell A P and Brantlinger A (2008) A pluralistic view of critical mathematics. In Proceedings of the Fifth International Mathematics Education and Society Conference (Albufeira, Portugal, 16-21 February), 424-433.

Reichenbach H (1938) Experience and Prediction: An Analysis of the Foundations and the Structure of Knowledge. Chicago, IL: University of Chicago Press.

Restivo S, Van Bendegem J P, and Fischer R (eds.) (1993) Math Worlds: Philosophical and Social Studies of Mathematics and Mathematics Education. Albany, NY: State University of New York Press.

Rosental C (2003) Certifying knowledge: The sociology of a logical theorem in artificial intelligence. American Sociological Review 68 (4): 623-644.

Rosental C (2008) Weaving Self-Evidence: A Sociology of Logic. Princeton: Princeton University Press.

Rota G-C (1991) The pernicious influence of mathematics upon philosophy. Synthese 88(2): 165-178.

Schickore J (2008) Doing science, writing science. Philosophy of Science 75(3): 323343.

Schoenfeld A H (1987) Pólya, problem solving, and education. Mathematics Magazine 60(5): 283-291.

Thurston W P (1994) On proof and progress in mathematics. Bulletin of the American Mathematical Society 30(2): 161-177.

Tymoczko T (ed) (1986) New Directions in the Philosophy of Mathematics: An Anthology. Boston: Birkhäuser.

Van Bendegem J P (1988) Non-formal properties of real mathematical proofs. In: Proceedings of PSA 1988 (Biennial Meeting of the Philosophy of Science Association), 249-254.

Warwick A (2003) Masters of Theory: Cambridge and the Rise of Mathematical Physics. Chicago: University of Chicago Press.

Watson H (1990). Investigating the social foundations of mathematics: Natural number in culturally diverse forms of life. Social Studies of Science 20(2): 283312.

Weber K (2004) Traditional instruction in advanced mathematics courses: A case study of one professor's lectures and proofs in an introductory real analysis course. Journal of Mathematical Behavior 23(2): 115-133.

Wilder R L (1981) Mathematics As A Cultural System. Oxford: Pergamon.

Wittgenstein L (1976) Wittgenstein's Lectures on the Foundations of Mathematics, Cambridge, 1939. Chicago: University of Chicago Press.

Greiffenhagen, C. and W. Sharrock (2011). Does mathematics look certain in the front, but fallible in the back? Social Studies of Science 41 (6), 839-866. 


\section{Biographical notes}

Christian Greiffenhagen is Simon Research Fellow at the University of Manchester, conducting ethnographic research on the work of discovery in professional mathematics. $\mathrm{He}$ is also involved in research exploring the impact of nanotechnologies on the European consumer market, a video-based investigation of ontology-based design in bioinformatics, and a comparative study of qualitative and quantitative reasoning in the social sciences. Recent publications include 'Unpacking tasks: the fusion of new technology with instructional work', Computer Supported Cooperative Work, 'Video analysis of mathematical practice? Different attempts to "open up" mathematics for sociological investigation', Forum: Qualitative Social Research, and 'Visual repairables: analysing the work of repair in human-computer interaction' (with Rod Watson), Visual Communication.

Wes Sharrock has been at the University of Manchester since 1965 and is currently Professor of Sociology. His long term interests have been in philosophy of the social sciences, sociological theory and methods, and research on conduct in organisational contexts. These interests have been most centrally realised by a concern with the issue of applying Wittgenstein's philosophy and ethnomethodology in sociological thought. Recent and current researches have been into mathematical practice and ontology building in informatics. Recent publications include Theory and Methods in Sociology, Palgrave Macmillan, 2007 (with J, Hughes), Brains, Mind and Human Behaviour in Contemporary Cognitive Science, Edwin Mellen, 2007 (with J. Coulter), 'The sociologist as movie critic', (with D. Randall) and 'Ethnomethodology and constructionist studies of technology' (with G. Button) in M. Rouncefield and P. Tolmie (eds), Ethnomethodology at Work, Ashgate, 2011. 